\title{
Phenotypic variation and detection of carrier status in the partial androgen insensitivity syndrome
}

\author{
J A Batch, H R Davies, B A J Evans, I A Hughes, M N Patterson
}

\begin{abstract}
The partial androgen insensitivity syndrome occurs in $46, X Y$ subjects with phenotypes ranging from perineoscrotal hypospadias with cryptorchidism and micropenis (mild undervirilisation) to clitoromegaly and partial labial fusion (marked undervirilisation). Within an affected family, wide variation in the degree of genital ambiguity between individuals can be seen. Two cousins of a previously reported subject who had severe genital ambiguity and partial androgen insensitivity were investigated. Neither of the cousins had genital abnormalities as marked as the index case, who also had qualitatively abnormal androgen binding and two mutations of the androgen receptor gene. Despite marked phenotypic differences between the index case and his cousins, similar androgen binding and the same androgen receptor mutations were shown in the cousins. Furthermore, one of the androgen receptor gene mutations has been shown in the mother and sister of one of the boys indicating that they are carriers. Thus phenotypic variation in families affected by partial androgen insensitivity is dependent on factors other than abnormalities of the androgen receptor gene alone. Although carrier status in partial androgen insensitivity can be determined, the severity of genital abnormalities in an affected offspring cannot be reliably predicted.
\end{abstract}

(Arch Dis Child 1993; 68: 453-457)

The partial androgen insensitivity syndrome is an $\mathrm{X}$ linked disorder of male genital development occurring in subjects with a 46,XY karyotype.' Partial androgen insensitivity syndrome comprises a wide phenotypic spectrum of disorders ranging from perineoscrotal hypospadias, bifid scrotum, and cryptorchidism to marked undervirilisation consisting of clitoromegaly and labial fusion. The complete androgen insensitivity syndrome also occurs and presents with a normal external female genital appearance.' It has been shown that complete and partial androgen insensitivity syndrome may be associated with defects in the androgen receptor. ${ }^{2}$ Androgen binding abnormalities have been detected in cell lines from androgen insensitive subjects and, more recently, mutations have been identified in the gene for the androgen receptor in affected subjects. ${ }^{3+}$ The androgen receptor gene is located on the $\mathrm{X}$ chromosome and is encoded by eight exons. ${ }^{56}$ Like other members of the steroid receptor superfamily, the androgen receptor protein is divided into three functional domains: the $\mathrm{C}$ terminal domain (encoded by exons $\mathrm{D}-\mathrm{H}$ ) is responsible for androgen binding, the central domain (exons B and $C$ ) consists of two zinc finger-like elements responsible for DNA binding, and the less well characterised $\mathbf{N}$ terminal domain (exon $\mathrm{A}$ ) has a role in transcriptional activation by the receptor. ${ }^{78}$

The androgen receptor gene mutations in a subject from a family with partial androgen insensitivity syndrome with seven affected males have been described. ${ }^{9}$ This subject had a point mutation (single nucleotide substitution) in exon $\mathrm{E}$ of the androgen binding domain of the androgen receptor gene resulting in a change from a tyrosine to a cysteine at amino acid 761 . In addition, the subject had a shortening of the hypervariable polyglutamine region of exon $A$ to 12 residues, which is at the lower end of the normal range defined for a number of groups. ${ }^{10}$ Expression studies of the mutant receptor showed that the two mutations interacted to cause the qualitative abnormalities in androgen binding seen in this patient. ${ }^{9}$

We have investigated two further subjects from this kindred and outline their clinical features, androgen binding studies, and androgen receptor gene analysis. Neither subject has a clinical phenotype as severe as the subject described previously. In addition, we have investigated the carrier status of the mother and sister of one of the affected subjects.

Subjects and methods

Figure 1 shows the family pedigree.

\section{SUBJECT III-1}

Subject III-1 was noted at birth to have penile hypospadias, a normal scrotum, and bilateral cryptorchidism. Male sex of rearing was assigned as the genitalia were unequivocally male. The

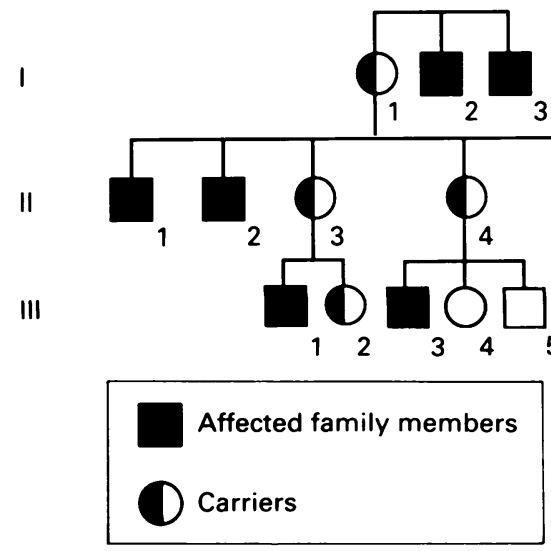

Figure 1 Pedigree of the family with partial androgen insensitivity syndrome and variable phenotype. 
Results of androgen binding assay. The androgen binding data for subjects III-I and III-3 are shown. The data were determined in different laboratories and appropriate normal ranges are given. The normal ranges for the assays are expressed as mean $(S D)$ and number of samples assayed

\begin{tabular}{llll}
\hline & $\begin{array}{l}\mathrm{B}_{\max } \\
\left(\times 10^{-18} \mathrm{~mol} /\right. \\
\mu g D N A)\end{array}$ & $\begin{array}{l}\mathrm{K}_{\mathrm{d}}\left(\times 10^{-10} M\right) \\
\text { Subject }\end{array}$ & $\begin{array}{l}\text { Thermolability } \\
(\% \text { reduction at } \\
\left.40^{\circ} \mathrm{C}\right)\end{array}$ \\
\hline III-1 & 1850 & $2 \cdot 2$ & 49 \\
Normal $(\mathrm{n}=9)$ & $1329(439)$ & $1 \cdot 07(0 \cdot 26)$ & $17(7 \cdot 5)$ \\
III-3 & 1990 & $4 \cdot 5$ & 65 \\
Normal $(\mathrm{n}=31)$ & $775(185)$ & $0 \cdot 88(0 \cdot 35)$ & $6(5)$ \\
\hline
\end{tabular}

karyotype was $46, \mathrm{XY}$, and because of the known family history, no other biochemical studies were carried out. A hypospadias repair and bilateral orchidopexy were performed.

\section{SUBJECT III-3}

Subject III-3 was noted at birth to have micropenis, perineal hypospadias, chordee, and a bifid scrotum. The testes were palpable in the inguinal canal. The severity of genital ambiguity was much less severe than III-6, and male sex of rearing was assigned. The karyotype was $46, X Y$, and endocrine investigation, including a human chorionic gonadotrophin stimulation test, was normal. A bladder mucosa graft hypospadias repair was performed. At the time of the operation the testes were descended into the scrotum.

\section{SUBJECT III-6}

The clinical features, endocrine evaluation, and androgen binding studies of subject III-6 have been described elsewhere. " Briefly, he had severe genital abnormalities consisting of extreme microphallus and perineoscrotal hypospadias. At birth, female sex of rearing was assigned. Further investigation, however, revealed a 46,XY karyotype and normal testosterone production and metabolism. Sex of rearing was changed to male at the family's request, though the prognosis for normal adult male genital function was guarded. His subsequent management and follow up have been outlined previously."

\section{TISSUE CULTURE}

Fibroblast cell lines were established from genital skin biopsy samples obtained at operation by primary explanation in E199 medium containing $20 \%$ fetal calf serum and supplemented with penicillin, streptomycin, and glutamine as described. ${ }^{12}$ The serum sample was reduced to $10 \%$ after the second passage and maintained at that level thereafter. Cells were grown at $37^{\circ} \mathrm{C}$ in $5 \%$ carbon dioxide.

\section{ANDROGEN BINDING ASSAY}

Androgen binding was measured in genital skin fibroblasts using whole cell binding assays. Results for subject III-3 have previously been included as part of another study. ${ }^{2}$ The androgen binding assay in subject III-1 was performed using a modification ${ }^{4}$ of a published method. ${ }^{12}$
Parameters derived from this assay included the receptor concentration $\left(B_{\max }\right)$, binding affinity $\left(K_{\mathrm{d}}\right)$ and the stability of androgen binding at $40^{\circ} \mathrm{C}$ (thermolability).

\section{POLYMERASE CHAIN REACTION SINGLE STRAND} CONFORMATION POLYMORPHISM ANALYSIS OF THE ANDROGEN RECEPTOR GENE

Genomic DNA was prepared from genital skin fibroblasts or whole blood by standard methods. ${ }^{13}$ The androgen receptor gene was screened for mutations using a rapid and sensitive technique: polymerase chain reaction (PCR) single strand conformation polymorphism (SSCP) as described elsewhere. ${ }^{+14}$

\section{DNA SEQUENCING OF POLYMERASE CHAIN} REACTION PRODUCTS

Preparative PCRs were carried out in a total volume of $100 \mu \mathrm{l}$ as scaled up versions of the reactions previously described. ${ }^{+}$After PCR, mineral oil was removed and the reactions were extracted once with $200 \mu \mathrm{l}$ chloroform. The volumes were then reduced to approximately 20 $\mu l$ under vacuum before loading on a $1 \%$ low melting point agarose gel. The excised gel bands were purified using a Magic PCR Preps DNA purification kit (Promega). Subsequently the sequencing reactions were carried out with the fmol DNA sequencing system (Promega) using the same primers as for the PCR. The primers were labelled with [ $\gamma^{32}$ P]ATP (Amersham). Standard conditions were used for sequencing gel electrophoresis. In all instances mutations were sequenced on both strands.

\section{Results}

The table summarises the results of androgen
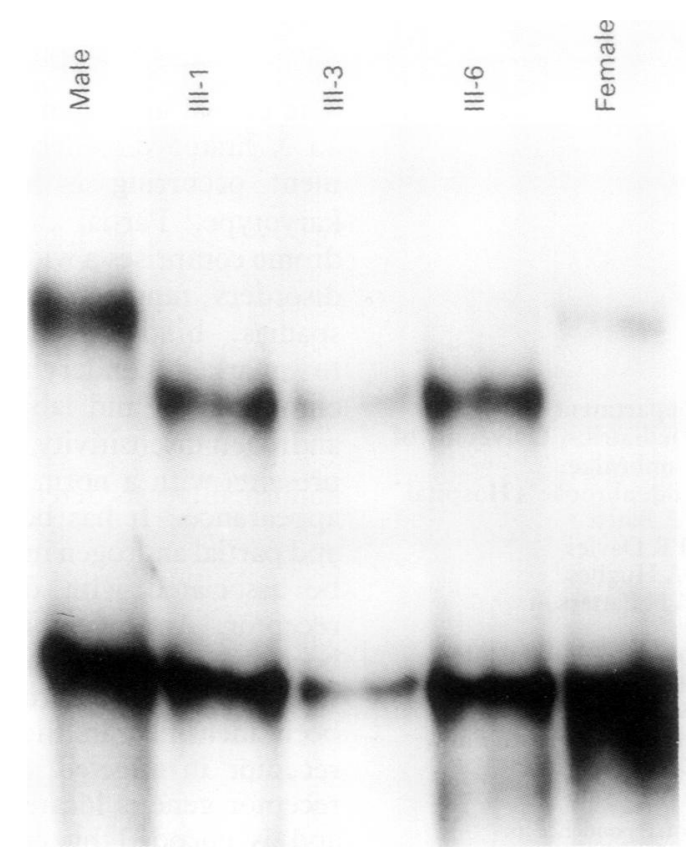

Figure 2 SSCP analysis of exon $E$ of the androgen receptor gene. An identical SSCP band shift is shown in the upper band of exon $E$ PCR products from subjects III-1, III-3, and III-6, suggesting that there is an abnormality of the androgen. receptor gene and that it is the same in the three subjects. 
A C G T

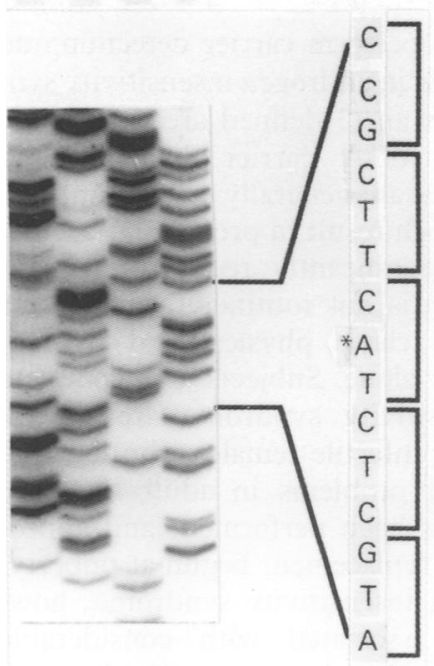

Control
3' Sense

Ala

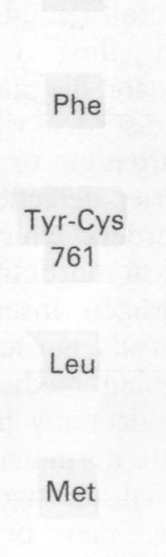

5' Sense
A C G T

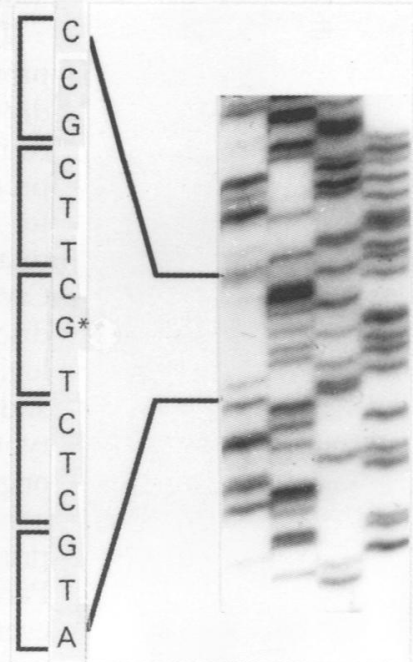

Mutant
Figure 3 Sequencing of exon $E$ of the androgen receptor gene in subject III-1. The same sequencing abnormality was detected in exon $E$ in subjects $I I I-1, I I I-3$, and III-6. The altered nucleotide is indicated by an asterisk. The resultant change in amino acid is also shown (Ala = alanine, Phe $=$ phenylalanine,$T y r=$ tyrosine, Cys $=$ cysteine, Leu $=$ leucine Met=methionine).

binding assays in subjects III-1 and III-3. The two subjects had a qualitative defect in androgen binding shown by the high $K_{\mathrm{d}}$ value (that is, low androgen binding affinity) and thermolability of binding. There was no quantitative abnormality of androgen binding. These results suggested that the two boys had an abnormal androgen receptor. Despite being performed in a different laboratory, androgen binding studies in subject III-6 showed similar androgen binding abnormalities to those of subjects III-1 and III-3. In subject III- 6 the qualitative abnormalities found were thermolability when the assay temperature was increased from 30 to $41^{\circ} \mathrm{C}$ and an increased dissociation rate of androgen from its receptor. " The dissociation constant was not measured.

As it was probable that rnembers of an affected kindred would share the same androgen receptor gene abnormalities, exons $\mathrm{A}$ and $\mathrm{E}$, the sites of the abnormalities in subject III-6, were examined first. ${ }^{9}$ Exon $\mathrm{E}$ was examined in all three subjects (III-1, III-3, and III-6) by SSCP. The presence of a mutation is indicated by a shift in the mobility of denatured PCR segments when run on a non-denaturing gel. Figure 2 shows the presence of an SSCP band shift in exon E fragments from subjects III-1, III-3, and III-6. The band shift is the same in all three subjects, suggesting that the mutation is the same. This abnormality was detected readily under the two sets of electrophoresis conditions. Direct sequencing of exon $\mathrm{E}$ in subjects III-1, III-3, and
III- 6 confirmed the presence of a point mutation (adenine to guanine) causing an amino acid change from tyrosine to cysteine at amino acid 761 (fig 3). The mutations were sequenced on the two strands. The region of exon A encoding the polymorphic glutamine repeat was also sequenced in subjects III-1, III-3, and III- 6 and in each instance 12 glutamine residues were found, which is at the lower limit of that defined for the normal population. ${ }^{10}$ No other mutations were found in these two exons in any of the subjects. In an attempt to determine a cause for the phenotypic variability in this family, the rest of the androgen receptor gene was also screened for mutations in the three subjects. No other SSCP abnormalities were detected in any part of the gene, suggesting that there was no other abnormality of the androgen receptor gene. Figure 4 summarises the androgen receptor gene abnormalities found in subjects III- 1 , III- 3 , and III-6.

Figure 5 shows the results of SSCP screening of exon $\mathrm{E}$ for detection of carrier status. The SSCP banding pattern of a normal control showed two bands. In addition, the PCR fragment from subject III-1 also showed two bands, one of which migrated at a different rate to the control DNA. Exon E PCR products from subject II-3 (mother) and III-2 (sister) had three bands, representing a combination of the normal and mutant patterns. This indicated that they are carriers of the exon $\mathrm{E}$ androgen receptor gene mutation.

\section{Discussion}

We have shown that subjects within a partial androgen insensitivity syndrome kindred may have a different severity of genital ambiguity despite similar androgen binding abnormalities and the same androgen receptor gene mutations. Phenotypic variation in other partial androgen insensitivity syndrome families has previously been reported, ${ }^{15} 16$ but no studies have unequivocally shown the same androgen receptor gene abnormalities in subjects within a family where the genital abnormality is so variable. The reason for the phenotypic variation remains uncertain, and is clearly dependent on more than androgen receptor gene abnormalities alone. We have screened the whole androgen receptor gene by SSCP in three members of this family and have shown the same abnormalities in each. As it has been shown that subjects within this kindred respond to large doses of androgens in vivo, and that cultured genital skin fibroblasts from an affected family member also respond to androgens in vitro, ${ }^{11}$ it may be possible that variable

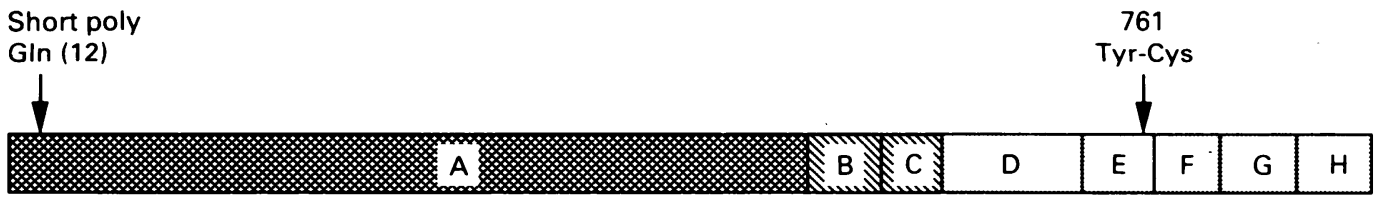

Figure 4 Summary of androgen receptor gene mutations found in this family. Shading indicates the major functional domains of the androgen receptor. The portions of the receptor encoded by each of the exons are boxed. There is a point mutation at position 761 , changing a tyrosine (Tyr) to a cysteine (Cys). In addition, there is shortening of the polyglutamine stretch in exon $A$ to 12 residues (Gln=glutamine). 


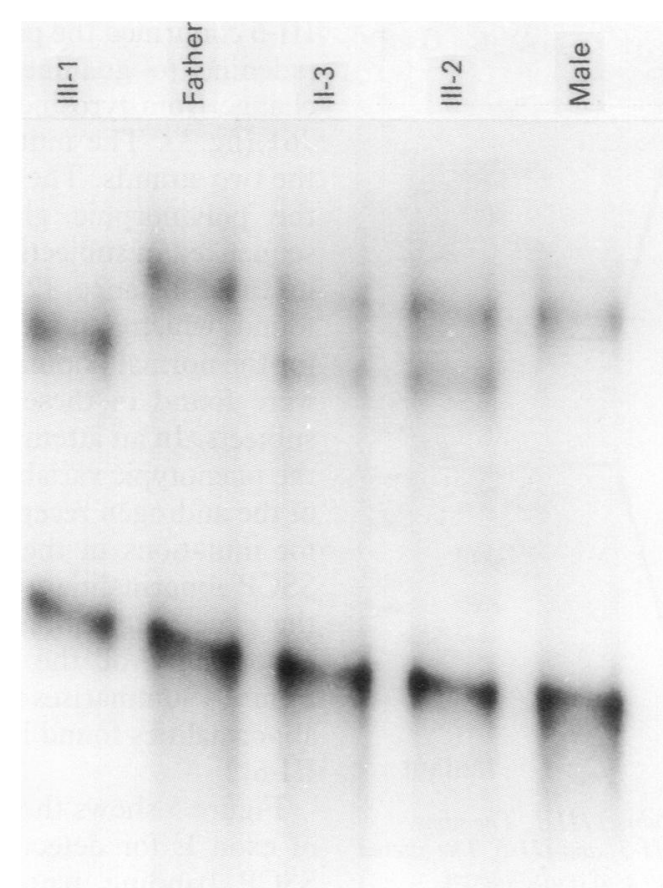

Figure 5 Use of SSCP for carrier detection of androgen receptor gene mutations. Subject III-I is affected and shows a single upper band. The unaffected subjects (father and male control) also show a single upper band, which migrates at a different rate in the gel. Subjects II-3 and III-2 have two upper bands, a combination of the normal and mutant bands, indicating that they are carriers of the mutation.

androgen production at a critical stage during in utero genital development has contributed to the spectrum of genital abnormalities seen in this family.

Single strand conformation polymorphism is a simple and reliable technique for the demonstation of androgen receptor gene abnormalities in carriers, and has allowed rapid analysis of DNA from female relatives of one of the affected boys. In this way we have shown that the subject's mother and sister are heterozygous carriers of the mutant allele. Other studies have also reported analysis of carrier detection in complete and partial androgen insensitivity syndrome, using analysis of the hypervariable polyglutamine region encoded by exon $\mathrm{A}^{9}$ or analysis of a $H$ ind III restriction fragment length polymorphism associated with the androgen receptor gene. ${ }^{17} 18$ Thus once the androgen receptor gene abnormality in an index case has been established, it is possible to offer reliable assessment of carrier status, genetic counselling, and prenatal diagnosis. ${ }^{19}$ Although the bulk of mutational analysis of the androgen receptor gene suggests that complete androgen insensitivity syndrome is due to mutations in the androgen receptor gene, the same cannot be said for partial androgen insensitivity syndrome. It is possible that partial androgen insensitivity syndrome may be caused by other genes involved in early development, particularly where no androgen binding abnormality is present. ${ }^{+}$In the situation where no androgen receptor gene abnormality had been detected in a partial androgen insensitivity syn- drome family, genetic counselling would be unreliable.

The ability to perform carrier detection and prenatal diagnosis in androgen insensitivity syndrome highlights an ill defined area of genetic counselling. Currently carrier detection and prenatal diagnosis are generally only performed for disorders which result in progressive mental retardation or significantly reduce longevity. Carrier detection is not routinely available for disorders which cause physical and psychological morbidity alone. Subjects with complete androgen insensitivity syndrome are phenotypically normal infertile females who have no ongoing medical problems in adult life once gonadectomy has been performed, and appropriate hormonal replacement begun at puberty. Partial androgen insensitivity syndrome, however, may be associated with considerable morbidity, beginning at birth and extending into adult life. Genital ambiguity in the neonatal period may result in delayed or even inappropriate gender assignment, thus causing the family emotional stress. After this, if the genital abnormality is severe, a series of complex corrective surgical procedures may be performed and still not achieve a satisfactory cosmetic and functional result. Poor pubertal virilisation and ongoing concern about infertility and the potential for gonadal malignancy may cause considerable psychological distress in adult life. As an example of a further complication, the family studied shows that subjects in a partial androgen insensitivity syndrome family with the same androgen receptor gene abnormalities may show considerable phenotypic variability. Thus it may not be possible to predict the severity of genital abnormality in partial androgen insensitivity syndrome on the basis of androgen receptor gene mutations detected prenatally in a fetus. The decision to perform carrier detection and ultimately prenatal diagnosis for the androgen insensitivity syndrome must therefore be based on the individual family and their informed attitude to the prospect of having an infant with either complete or partial androgen insensitivity. This work was supported by the Medical Research Council and the
Wellcome Trust. JB was supported by grants from the Smith and Wellcome Trust. JB was supported by grants from the Smith and
Nephew Foundation, the University of Melbourne, Australia (The Henry and Rachael Ackman Travelling Scholarship in Medicine), the Royal Australasian College of Physicians (CRB Blackburn Scholarship), and the Royal Children's Hospital, Melbourne (Uncle Bob's Scholarship). Dr Martin Savage and Mr Philip Ransley are gratefully acknowledged for submitting samples from their patients. We are also grateful to Dr Eamonn Maher for helpful discussions.

1 Batch J, Patterson M, Hughes I. Androgen insensitivity syndrome. Reproductive Medicine Reviews 1992; 1: 131-50.

2 Hughes I, Evans B. Androgen insensitivity in forty-nine patients: classification based on clinical and androgen patients: classification based on clinical and

3 McPhaul M, Marcelli M, Tilley W, Griffin J, Wilson J. Androgen resistance caused by mutations in the androgen Androgen resistance caused by mutations
receptor gene. FASEB F 1991; 5: 2910-5.

4 Batch J, Williams D, Davies H, et al. Androgen receptor gene mutations identified by SSCP in fourteen subjects with androgen insensitivity syndrome. Human Molecular Genetics 1992; 1: 497-503.

5 Chang C, Kokontis J. Liao S. Molecular cloning of human and rat complementary DNA encoding androgen receptors. Science 1988; 240: 324-6.

6 Lubahn D, Joseph D, Sullivan P, Willard H, French F, Wilson $E$. Cloning of human androgen receptor complementary DNA and localization to the $x$ chromosome. Science 1988; 240: 327-30.

7 Simental J, Sar M, Lane M, French F, Wilson E. Transcriptional activation and nuclear targeting signals of the human androgen receptor. F Biol (Chem 1991; 266: 510-8. 8 Jenster G, van der Korput H, van Vroxonhoven $C_{\text {, van der }}$
Kwast T, Trapman J, Brinkmann A. Domains of the human 
androgen receptor involved in steroid binding, transcriptional activation, and subcellular localization. Mol Endrocrinol 1991; 5: 1396-404.

9 McPhaul M, Marcelli M, Tilley W, Griffin J, Isidro-Gutierrez R, Wilson J. Molecular basis of androgen resistance in a family with a qualitative abnormality of the androgen receptor and responsive to high-dose androgen therapy. f Clin Invest 1991; 87: 1413-21.

10 Edwards A, Hammond H, Jin L, Caskey T, Chakraborty R. Genetic variation at five trimeric and tetrameric tandem repeat loci in four human population groups. Genomics 1992 12: 241-53.

11 Grino P, Isidro-Gutierrez R, Griffin J, Wilson J. Androgen resistance associated with a qualitative abnormality of the androgen receptor and responsive to high dose androgen therapy. F Clin Endocrinol Metab 1989; 68: 578-84.

12 Evans B, Jones T, Hughes I. Studies of the androgen receptor in dispersed fibroblasts: investigation of patients with in dispersed fibroblasts: investigation of patients with

13 Sambrook J, Fritsch E, Maniatis T. Isolation of high molecular weight DNA from mammalian cells. In Molecular cloning. Cold Spring Harbor, NY: Cold Spring Harbor Laboratory Press, 1989: 9.14-9.23.
14 Orita M, Suzuki Y, Sekiya T, Hayashi K. Rapid and sensitive detection of point mutations and DNA polymorphisms using the polymerase chain reaction. Genomics 1989; 5: 874-9.

15 Wilson J, Harrod M, Goldstein J, Hensell D, MacDonald P. Familial male pseudohermaphroditism, type 1: evidence for androgen resistance and variable clinical manifestations in a family with the Reifenstein syndrome. N Engl F Med 1974; 290: 1097-103.

16 Walker A, Stack E, Horsfall W. Familial male pseudohermaphroditism. Med $\mathcal{F}$ Aust 1970; i: 156-60.

17 Brown C, Goss S, Lubahn D, et al. Androgen receptor locus on the human X chromosome: regional localization to Xq11-12 and description of a DNA polymoprhism. Am f Hum Genet 1989; 44: 264-9.

18 Quigley C, Friedman K, Johnson A, et al. Complete deletion of the androgen receptor: definition of the null phenotype of the androgen insensitivity syndrome and determination of the androgen insensitivity syndrome and determination

19 Zoppi S, Marcelli M, Harbison M, et al. Androgen resistance arising from an $\mathrm{N}$-terminal truncation of the androgen receptor: prenatal diagnosis. $\mathcal{F}$ Cell Biochem 1992; suppl 16C: 32.

Neurokinin receptor antagonism in asthma

The basic mechanisms which lead to wheezing in asthma are undoubtedly complex and new avenues of treatment continue to be explored. Recent work from Japan (Masakazu Ichinose and colleagues, Lancet 1992; 340: 1248-51) concentrates on the possibility that one factor in airway inflammation may be an axon reflex which results in the antidromic release of neuropeptides from vagal nerve endings. Among these neuropeptides are the tachykinins, substance $\mathbf{P}$ and neurokinin $\mathbf{A}$. A cyclopeptide (FK-224) derived from the fermentation product of Streptomyces violaceusniger has been shown to act as a tachykinin receptor antagonist. Inhaled bradykinin is a potent bronchoconstrictor in people with asthma ${ }^{1}$ but not in others and it is postulated that the bronchoconstriction may be mediated, at least in part, by bradykinin-induced release of tachykinin at sensory nerve endings.

Dr Ichinose and his colleagues studied 10 patients aged between 18 and 55 years with asthma. In a double blind, crossover trial each patient received inhaled bradykinin in gradually increasing doses beginning 25 minutes after the inhalation of either FK-224 or placebo. The bronchoconstrictor response as shown by the fall in specific airway conductance (sGaw) measured by whole body plethysmography was less severe after FK-224. The mean cumulative concentration of bradykinin needed to produce a $35 \%$ fall in sGaw was $5.3 \mu \mathrm{g} / \mathrm{ml}$ after placebo and $40 \mu \mathrm{g} / \mathrm{ml}$ after FK-224 $(p<0.001)$. Coughing induced by the inhalation of bradykinin was prevented by pretreatment with FK-224.

The results give support to the hypothesis that neurogenic inflammation mediated by tachykinins might be involved in the asthmatic process and tachykinin antagonists could prove to be useful in the treatment of asthma.

ARCHIVIST

1 Barnes PJ. Bradykinin and asthma. Thorax 1992; 47: 979-83. 